\title{
AN AUTOMATIC (OR SEMI-AUTOMATIC) APPARATUS FOR THE DETERMINATION OF MELTING CURVES
}

\author{
by \\ W II SMIT ANDG KAITEMAN \\ Netherlands Central Instunte for Physicochemical Constants, Utrecht (The Netherlands)
}

\section{INTRODUCTION}

The apparatus to be described is a "thin film" apparatus operating automatically within a range of about $02^{\circ} \mathrm{C}$ and a temperature sensitivity of about $000{ }^{\circ} \mathrm{C}$. I.arger temperature ranges may be investigated, either fully automatically with a temperature sensitivity which is inversely proportional to the temperature range to be investigated, or semi-automatically by dividing the temperature range into parts of about $0.2^{\circ} \mathrm{C}$ In the lat ter case the temperature sensitivity remains 0 oor ${ }^{\circ} \mathrm{C}$.

The calorimetric part of the apparatus is essentially the same as that of the handoperated apparatus, mentioned in previous papers 1 Since up to now we have not given any account of the principles on which the "calorimeter" is based, it seemed useful to begin by doing so and then to describe an adapted system of controlling and recording.

\section{Principle of the apparatus}

The "calorimeter" consists of a cylindrical metal block containıng a coaxial cylındrical air space. The substance to be investigated is contained in an annular space between the "thermometer" and the inside wall of the measuring vessel The axis of the measuring vessel coincicles with the axis of the block.

The metal block is heated at such a rate that its temperature differs constantly, by a distunct number of degrees, from the temperature indicated by the central thermometer. Consequently the flow of heat from the wall of the block to the measuring vessel (or reverse) is almost constant.

This method as such for obtaining a constant heat supply has already been applied by THOMAS AND PARKs'2.

In the apparatus described here the substance is spread in a single thin layer and no stırring is applied. In the hand-operated apparatus the temperatures of the block and the measuring vessel are indicated by mercury thermometers (A special type of small Beckmann thermometer, subdivided in $0.05^{\circ} \mathrm{C}$, rendered good service.)

In the automatic apparatus resistance thermometers have been applied. The resistance of the inner thermometer is recorded as a function of time, whereas the controller for heating the block operates on the difference of the specific resistance of the outer and inner thermometer. 
Description of the calormeter

The calorimeter (sec Iìg. I) consists of an aluminium cylındrical block (5) with a central bore, closed by a forced-in aluminium cover. A hole in this cover permits introduction of the glass measuring vessel (6) When in use the measuring vessel contains a

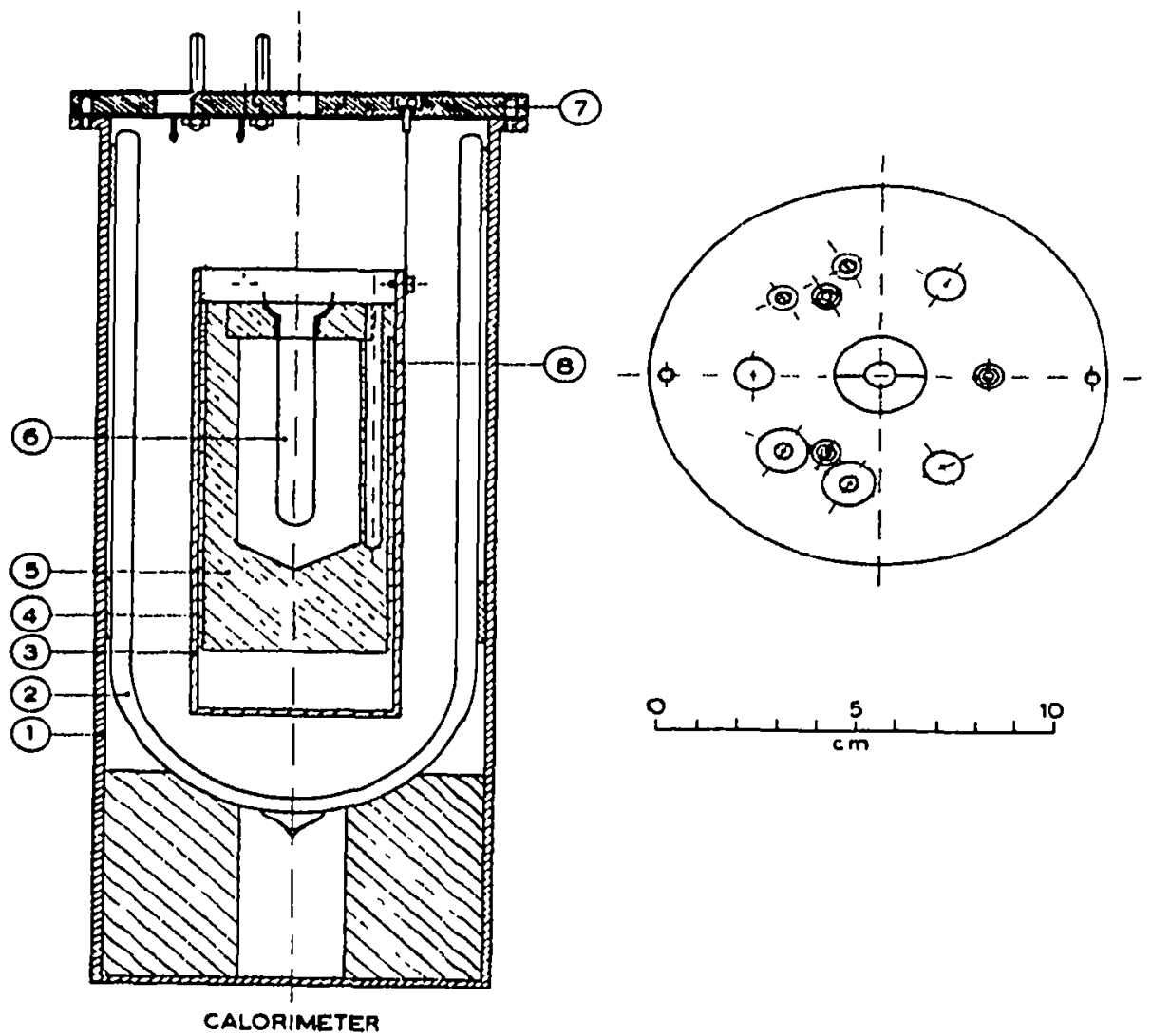

Fig I

(central) thermometer. A sccond (outer) thermometer may be inserted in a thermometer well (8). The block (5) is surrounded by a heating element (4) (40) ohms); this consists of a heating coil of constantan strip insulated by glass wool The coil is enclosed between two single layers of thin asbestos paper. The block, together with the heating element, is contained in a closcly fitting cylindrıcal aluminıum jacket (3). It is suspended to the large asbestos cement cover $(7)$ by means of thin stainless steel rods. The cover (7) rests on the outer jacket ( 1 ) containing the Dewar flask (2).

\section{Dimenszons of the measurzmg vessel}

The considerations on which the dimensions of the measurıng vessel, the layer of substance, and the thermometer, were based are given in the accompanying paper ${ }^{3}$. 


\section{Dimensions of the block}

The outer dimensions of the measuring vessel having been decided on, the optimal dimensions of the block were estimated on the basis of the following considerations.

Asis obvious, the heat supplied to the measuring vessel increases when the temperature difference between the block and the measuring vessel is increased. In order to obtain a reliable heating curve the heat supply, and thus the temperature difference, should be low. On the other hand, a low temperature difference involves great demands on the sensitivity of the system controlling this temperature difference. The accuracy aimed at, combined with the sensitivity of the controlling system set a lower limit for the allowable temperature difference Therefore, it is worthwhile to investigate at what dimensions of the metal block the heat supply to the measuring vessel is minimal at a given temperature difference.

Heat is transferred from the inside wall of the block to the measuring vessel by means of conduction and radiation (Since the temperature differences occurringare relatively small, convection is neglected)

As the length of the cylindrical bodies amounts to several times their respective diameters it is permissible to estimate the heat transfer to the measuring vessel by applying the laws obtaining to coaxial cylindrical bodies of infinite length.

The heat $(Q)$ transferred per unit time and per unit length to the inner cylinder of a system of two coaxial cylinders scparated by an annular air space amounts to

$$
Q=\frac{2 \pi \lambda\left(r_{2}-l_{1}\right)}{\ln r_{2} / r_{1}}+2 \pi r_{1}\left|\left(\begin{array}{c}
r_{2} \\
100
\end{array}\right)^{4}-\left(\begin{array}{c}
r_{1} \\
100
\end{array}\right)^{4}\right| c \text { cal/4ec cm* }
$$

where the first tern of the right-hand member represents the heat transferred by conduction and the second term represents the contribution of radiation, and

$$
\dot{c}=\frac{1}{c_{1}}+r_{1} r_{2}\left(\begin{array}{l}
1 \\
c_{2}
\end{array}-\frac{1}{c_{3}}\right)
$$

liurther $\lambda$ is the heat conductivity of air

$r_{1}$ is the outer radius of the inner cylinder (measuring vessel)

$r_{2}$ is the inner radius of the outer cylinder (metal block)

$T_{1}$ absolute temperature at $r_{1}$

$T_{2}$ absolute temperature at $r_{2}$

$C_{s}$ is the black body emissivity

$C_{1}$ is the emissivity of the surface of the inner cylinder

$C_{2}$ is the emissivity of the inner surface of the outer cylinder

\section{Discussion of equalion (I)}

As is clear from equation ( $I$ ), the heat transferred to the measuring vessel depends on quite a number of factors, viz., $C_{1}, C_{2}, \lambda, r_{1}, r_{2}, T_{1}$ and $T_{2}$

$C_{1}$ represents the emissivity of the outer wall of the measuring vessel. A glass measuring vessel is easy to make and permits inspection of the sample. The high emissivity of glass is a drawback that may be compensated to a large extent when the emissivity of the block $\left(C_{2}\right)$ is low. It was therefore decided to choose a glass measuring vessel, thus fixing the value of $C_{1}$ at $0.94 C_{s}$, which is the value obtaining for glass.

\footnotetext{
- Sce eg a Schack, Der Indusivielle Warmezibergang. Dusseldorf, 1953

W H Mc ADAMs, Heat Transmission, New York, i942

References $p 272$
} 
The influence of the remaining factors is illustrated by a series of graphs (see Figs. $2,3,4,5)$

Fig 2 shows the flow of heat $(Q)$ as a function of $r_{2}$ at different values of $C_{2}\left(r_{1}=\right.$ $0.4 \mathrm{~cm} ; T_{1}=573^{\circ} \mathrm{C} ; T_{2}=574^{\circ} \mathrm{C}$, and $\lambda=10^{-4} \mathrm{cal} / \mathrm{cm}$.sec degree.) It appears that a low value of $C_{2}$ is preferable.

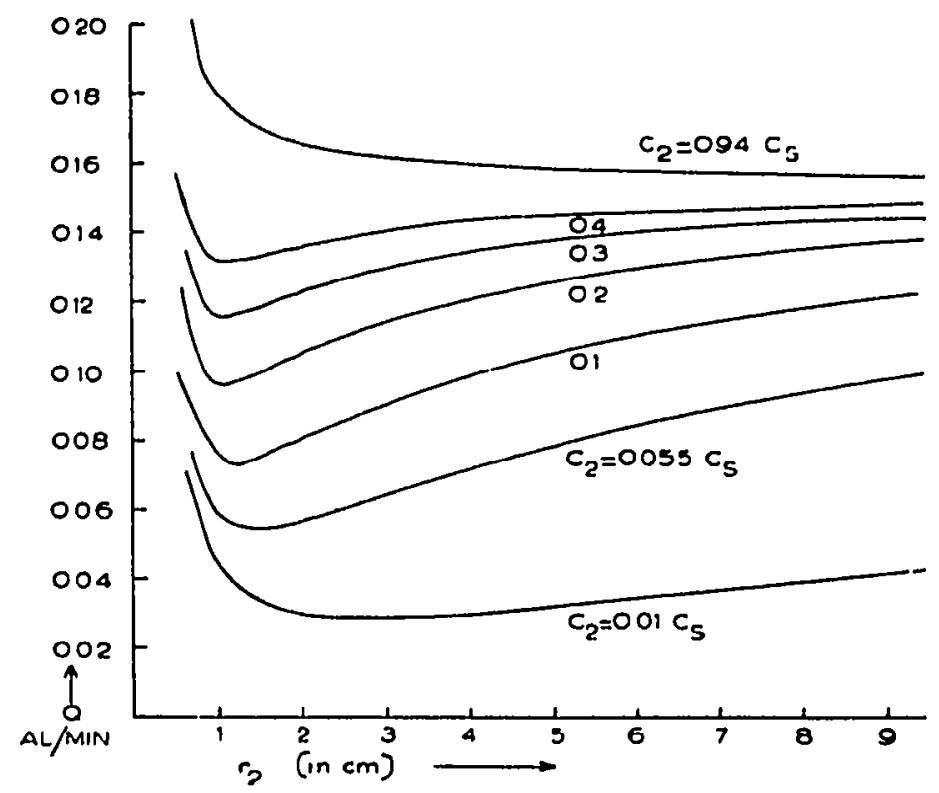

fig 2 Flow of heit as function of inner radius of calorimeter at clifferent emissivities

Polished surfaces of several metals have a low emissivity. However, the emissivity of thesc surfaces soon increases when ex posed to the atmosphere of a laboratory at elevated temperatures, with the exception of surfaces of gold or non-polished aluminium. Nonpolished aluminum has a fairly low emissıvity, viz, $C_{2}=0.055 C_{s}$. Further, aluminıum has a high temperature conductivity and is inexpensive. Accordingly, the block was made of aluminum, thus fixing the value of $C_{2}$ at about $0.055 C_{s}$. The curve of Fig. 2 obtaning for $C_{2}=0055 C$ s shows a minimum at $r_{2}=1.5 \mathrm{~cm}$.

Fig. 3 shows the flow of heat $(Q)$ as a function of $r_{2}$ at different temperatures. The curves of this graph hold good for $C_{1}=0.94 C_{s}, C_{2}=0.055 C_{s} ; r_{1}=0.4 \mathrm{~cm}$ and $T_{2}-T_{1}=$ $\mathrm{I}^{\circ} \mathrm{C}, \lambda$ is a temperature function varying from $0.5 \cdot 10^{-4}$ at $273^{\circ} \mathrm{K}$ to $\mathrm{IO} \mathrm{O}^{-4} \mathrm{cal} / \mathrm{cm} . \mathrm{sec}$ degree at $573^{\circ} \mathrm{K}$. (The applicable values of $\lambda$ have been derived from Landolt-Bornstein, Physikalisch-Chemische Tabclle.)

All the curves of Fig. I show a minimum. The minima have been connected by a dotted linc. It appears that the minma at low temperatures are far less pronounced than those at high temperatuies The value of $Q$ at $r_{2}=1.5 \mathrm{~cm}$ differs only slightly from the minimal value obtainable at a certain temperature within the range of $173-573^{\circ} \mathrm{K}$. Therefore a value of $r_{2}=1.5 \mathrm{~cm}$ may be preferable. However, it must be remembered that $Q$ is also a function of $r_{1}$ (see Fig. 5).

Fig. 4 shows $Q$ as a function of $r_{2}$ at different values of $T_{2}-T_{1} \cdot\left(C_{2}=0.055 C_{s} ; r_{1}=\right.$ $0.4 \mathrm{~cm}, I_{1}=573^{\circ} \mathrm{K} ; \lambda=I 0^{-4} \mathrm{cal} / \mathrm{cm}$. sec degree.) It appears that the minimum in the References $p \quad r 72$ 


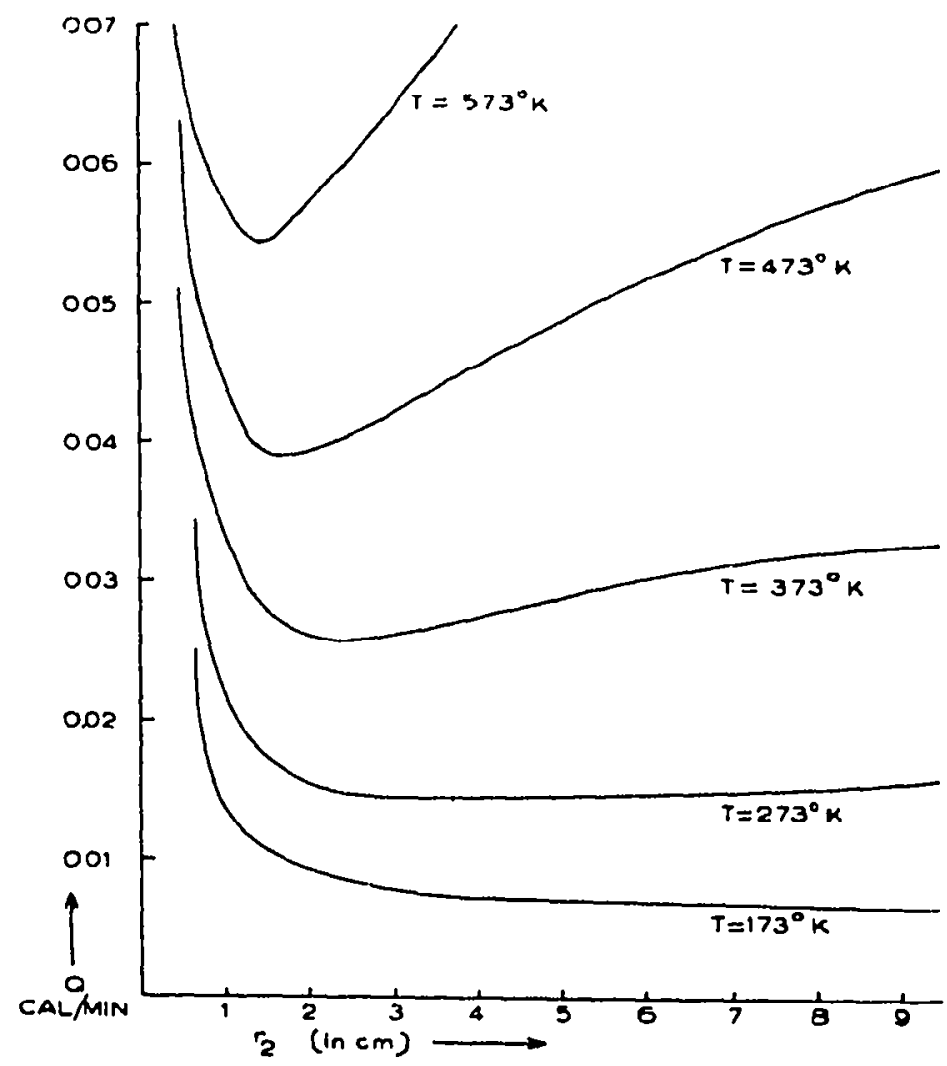

Fig 3. Fiow of heat at (lifferent temperature as function of inner radius

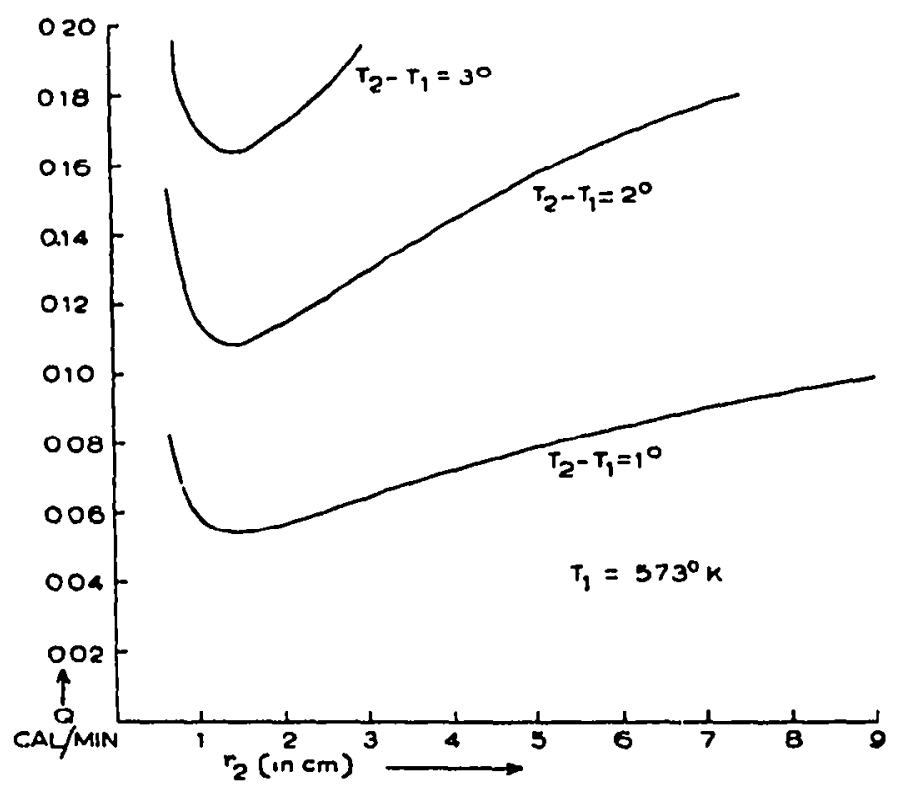

Fig. 4 Flow of heat at different thermal heads as function of inner radius. 
$(Q, r)$ curves is independent of $T_{2}-Z_{1}$. Further, $Q$ is approximately proportional to $\Gamma_{2}-T_{1}$, at least when $\left(T_{2}-T_{1}\right)<3{ }^{\circ} \mathrm{C}$

Fig 5 shows $Q$ as a function of $r_{2}$ at different values of the outside diameter $\left(r_{1}\right)$ of the measuring vessel $\left(C_{2}=0.055 C_{s}, T_{1}=573^{\circ} \mathrm{C}, T_{2}=574^{\circ} \mathrm{C}, \lambda=10^{4} \mathrm{cal} / \mathrm{cm}\right.$. sec degrec.)

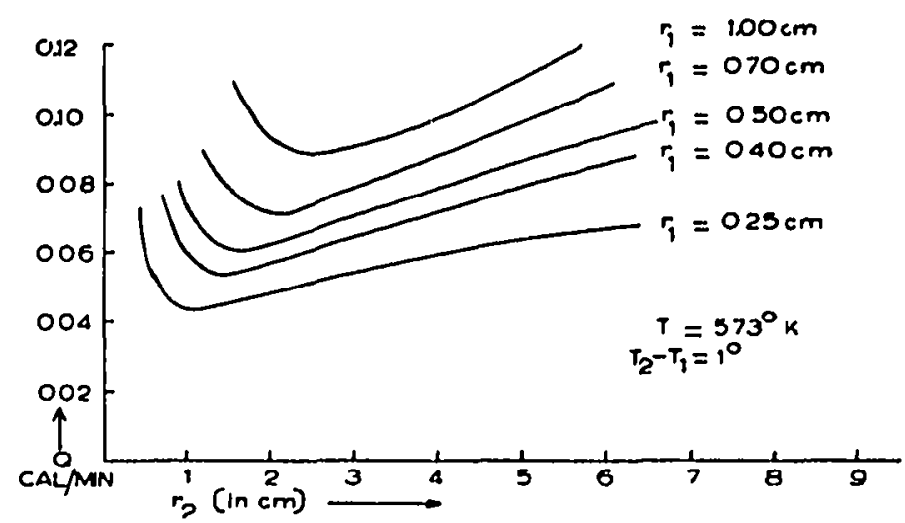

rig 5 lijow of hert a.4 function of inner radius at different rachi of the measuring vessel

It appears that the minimum in the $\left(Q, r_{2}\right)$ curves shifts to higher values of $r_{2}$ when $r_{1}$ increases. Therefore the inner radius of the block should be adapted to the outer radius of the measuring vessel. In its turn the outer radius of the measuring vessel depends on the radius of the thermometer (sec preceding paper). The radil of suitable mercury thermometers vary from about 0.2 to $0.4 \mathrm{~cm}$. (As will be shown, it is possible to construct resistance thermometers with comparable radi1.) This range of thermometer radii corresponds to a range of vessel radi from about 0.25 to $05 \mathrm{~cm}$ Within this range of vessel radı the value of $r_{2}$ at which $Q$ is minimal varies only from $\mathrm{r} .3$ to I $7 \mathrm{~cm}$. Thercfore an inside radius $\left(r_{2}\right)$ of the block equal to $1.5 \mathrm{~cm}$ has been chosen, this bcing a mean value permitting the use of commercially avallable thermometers and ensuring a low heat transfer within a very wide range of temperat ure.

\section{Experimental checks on equation $(T)$}

Experimental checks on equation ( $I$ ) have been carried out with aluminum blocks having inner radı of 1.0 and $1.5 \mathrm{~cm}$, respectıvely. Further, all-glass apparatuses $\left(C_{2}=\right.$ $\left.0.94 C_{s^{\prime}}\right)$ with inside radii $r_{2}$ of $(' .9, r . \mathrm{r}, \mathrm{x} .5$ and $\mathrm{r} .8 \mathrm{~cm}$, respcctively, have been investigated. The flow of heat (per unit length of the measuring vessel) during each experiment has been determmed by measuring the time required to melt a known amount of substance (per unit length) having a known heat of fusion The experiments have been carricd out at $T_{1}=321^{\circ} \mathrm{K}$ or $425^{\circ} \mathrm{K}$, and values of $\Gamma_{1}-T_{2}$ equal to $20,2.2,2.5$ and $3^{\circ} \mathrm{C}$ have been applied. 'The difference between the flow of heat actually found in this series of ten experiments never differed in any of the cases more than $10 \%$ from the value calculated. 


\section{MEASURING AND CONTROLLING PARTS}

\section{Temperalure detectzon system}

Electrical detection of temperature and temperature differences may be carried out either with thermocouples or with resistance thermometers In the case to be cliscussed here the accuracy aimed at is $0001^{\circ} \mathrm{C}$ corresponding with an e.m.f. or $5 \mathrm{IO}^{-8} \mathrm{~V}$ for a copper-constantan couple

It is very difficult to build a both stable and linear D C. amplifier with a noise level as low as $5 \cdot 10^{-8} \mathrm{~V}$ According to our experience it is possible to build a linear D.C. amplifier stable withın $10^{-6} \mathrm{~V}$ without using selected amplifier tubes. Accepting the value of ro $^{-6} \mathrm{~V}$ as a reasonable lower limit involves the use of a 20 -fold thermocouple to obtain an accuracy of $\mathrm{o} O \mathrm{or} \mathrm{I}^{\circ} \mathrm{C}$. A 20 -fold thermocouple, however, if applicd in our calorimeter, would upset the whole system of heat transfer because of the relatively large heat concluctivity of such a thermopile. Other drawbacks of a thermopile are its rclatively large volume and the necessity of a reference point constant within 0 vOI ${ }^{\circ} \mathrm{C}$

Resistance thermometers seem to be more suitable. N.'I.C. resistors (thermistors) were rejected because of their relatively small temperature range, instability at temperatures above $100^{\circ} \mathrm{C}$, and complicated temperature function The requirements to be met by a resistance thermometersuitable for our purposes are high temperature coefficient, high resistance and small volume

It appeared that these requirements could be met with by selfmade resistance thermometers with a resistance wire of tungsten or platınum.

\section{The resistance thermonicter}

The total resistance required has been calculated in the following way. Suppose the resistance thermometer to be part of a Wheatstone bridge consisting of four almost equal resistors Then the bridge signal varies with $\frac{1}{a} V$ volts per degree, when $V$ is the voltage applied to the bridge and $\alpha$ is the temperature cocfficient of the resistance thermometer. Because of the accuracy aimed at and the noise level of the amplifier, the variation of the bridge signal should be larger than $10^{-3}$ volt degrec. Since $\alpha$ equals about $0.4 \%$ per degree for tungsten or platınum the voltage fed to the bridge should be at least equal to one volt, causing a voltage over the resistance thermometer of about 0.5 volts Suppose the bridge to be fed with direct current and the resistance of the thermometer to be $k$ ohms. Then the heat developed by the thermometer amounts to $(0.25 R \times 0.24 \mathrm{cal} / \mathrm{sec}$. The total heat required for heating the measuring vessel and $i$ ts contents amounts to about $10^{-3} \mathrm{cal} / \mathrm{sec}$ not allowing more then $10 \%$ of the total heat required to be developed by the resistance thermometer. A value for $R$ of at least 600 ohms results.

The size of the sensitive part of the resistance thermometer should preferably be comparable with the bulb of a common mercury thermometer.

It appeared that 5-watt glow lamps contained a coll of tungsten wire having a resistance of about 600 ohms at room temperature The length of the coll is about $9 \mathrm{~cm}$ and its diameter is only o.I mm. It proved to be possible to mount such a coil in a helix etched in a small glass tube and to seal the whole in a second thin-walled glass tube of a slightly larger diameter. The ends of the tungsten coll were silver-soldered to platinum leads through the outer glass tube. We also constructed platinum resistance thermometers of comparable size and resistance in almost the same way. Platinum

References $p \quad r 72$ 
wire of a diameter of $0.015 \mathrm{~mm}$ was used. It was wound bifilarly around a glass tube having an etched helix of about three turns per $\mathrm{mm}$. The temperature-sensitive part of these thermometers has a diameter of about $65 \mathrm{~mm}$ and a length of about $25 \mathrm{~mm}$. The resistance at room temperature is about 600 ohms.

\section{Circuits for measurnig and controlling}

I he circuits for measuring and controlling start with two combined Wheatstone bridges shown in Tig. 6. The measuring bridge (bridge I) consist s of two resistance boxes ( $R_{1}$ and $R_{2}$, both IO $\times$ IOO ohm), a five-decades resistance box $\left(R_{3}\right)$ and the measuring thermometer $R_{\#}$ The controllıng bridge (bridge II) contans the box $\left(R_{1}\right)$, the measuring thermometer, the controlling thermometer and a five-decades resistance box $\left(R_{A}\right)$ Both bridges are fed from the same lead accumulator via a Poggendorf circuit (resistance 21) ohms) permitting the application of the following voltages to the bridge 2 , I, and $0.7 \mathrm{~V}$.

The two briclge signals are fed either to two totally separated amplifiers or to a motordriven switch which connects alternatively the first or the second bridge to one and the same amplifier. When only one amplifier is used the output of the amplifier is also fed to a switch operating in phase with the input switch. Dead periods are included so as to prevent measuring signals from interfering with controlling signals or reverse. The switches operate at three complete cycles per second.

Both methods of amplification (one or two amplifiers) have becn used. Amplification with two separate amplificrs showed to be somewhat advantageous.

The amplified measuring signal is fed to a commercial recorder. Since the output signal amounts to about 2 watt/degrec, even recorders without amplification system may be adapted to the amplifier.

The amplified controlling signal (d c ) is fed to the primary winding of a transformer. The scconclary winding of this transformer is inserted in the circuit containing the heating element of the block. Consequently, when the controlling signal (d.c.) increases, the impedance in the circuit of the heating current (a.c.) decreases, thus causing an increase of the licating current. Reverscly, a decrease of the controlling signal causes a decrease of the heating current, thus yielding a nice system of proportional control.

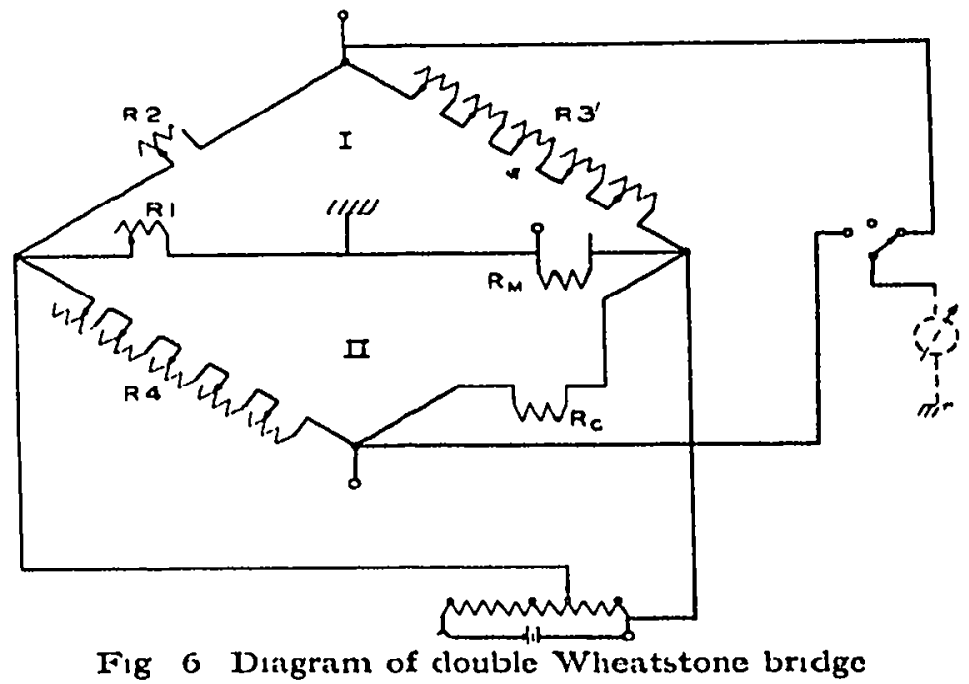

References p r7a 


\section{The ampltizer(s)}

The d.c signal coming from one of the bridges is fed to a chopper in order to convert d.c. into a c. After amplification the a.c signal is again converted into a d c signal by a second chopper operating at the same frequency. The choppers are driven by the same synchronous motor. The frequency of the choppers is 40 hertz

The scheme of a double-purpose (switch-operated) amplifier is shown in Fig. 7

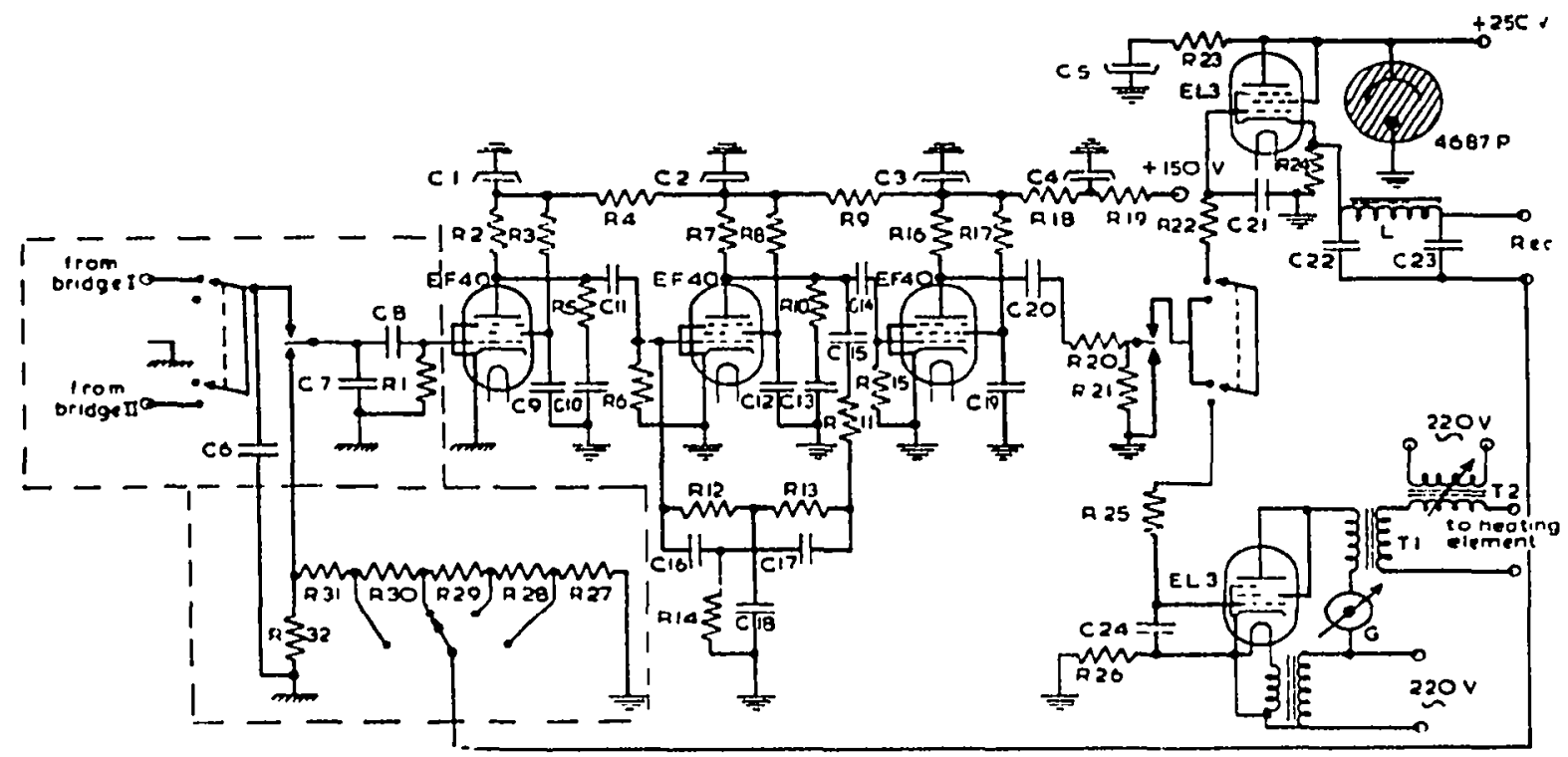

Fig 7 Scheme of microvolt amplifier, controlling and recording system

TAIBL_L: I

RESISTANCES AND CAPACITIIS ORTAINING TO IIG 7

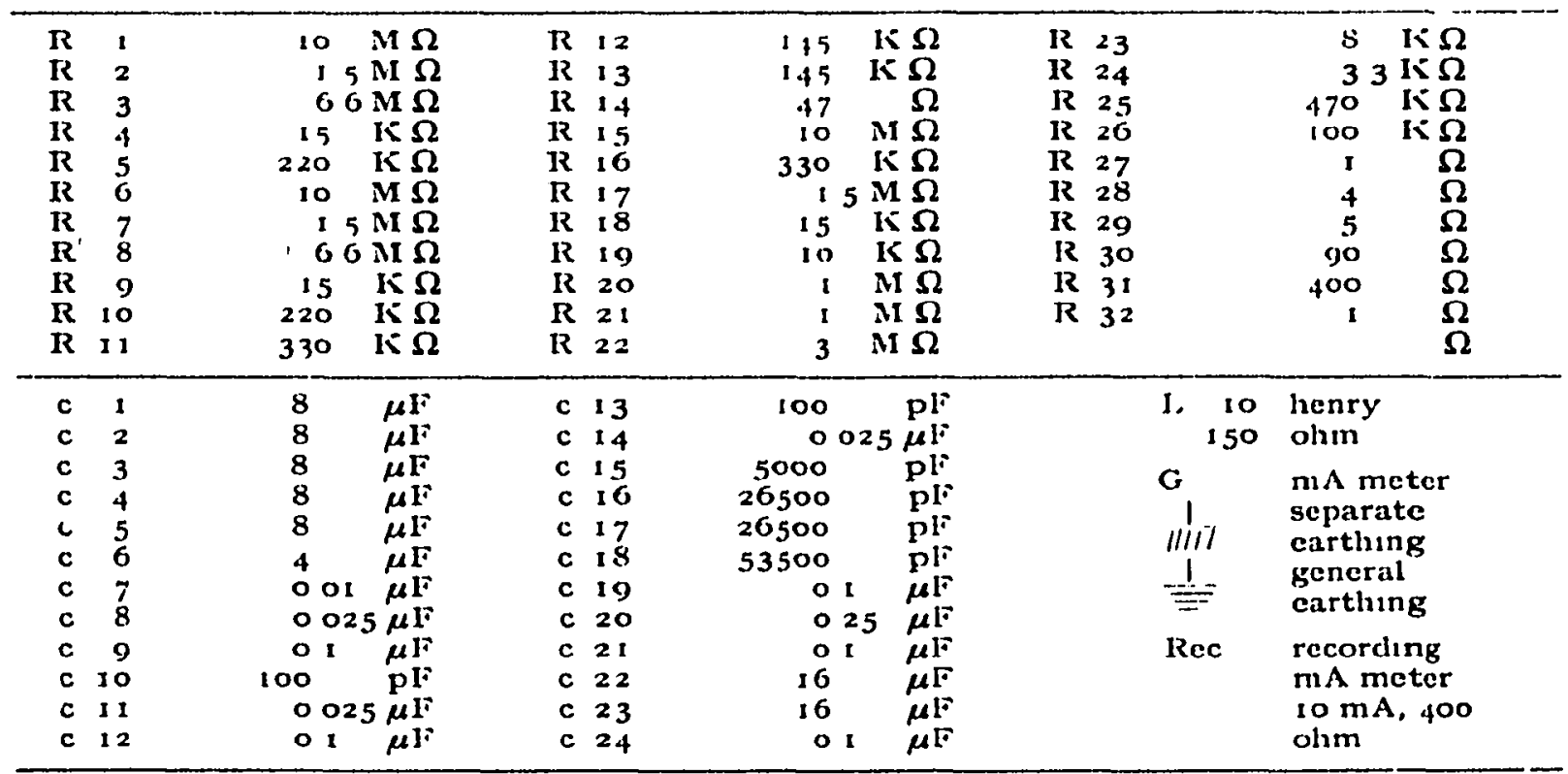


Since voltages as low as $\mathrm{IO}^{-6}$ are amplified, special attention has to be paid to shielding and earthing. 'The parts to be shielded have been enclosed in broken lines in the diagram. rwo different symbols for earthing have been used indicating two separated earthing circuits. When no scparate carthing is applied serious difficulties arise.

\section{The choppers}

The choppers (see Fig 8) used, are not unlike the one described by Liston, QuiNN, SARGEANT ANID SCOTT".

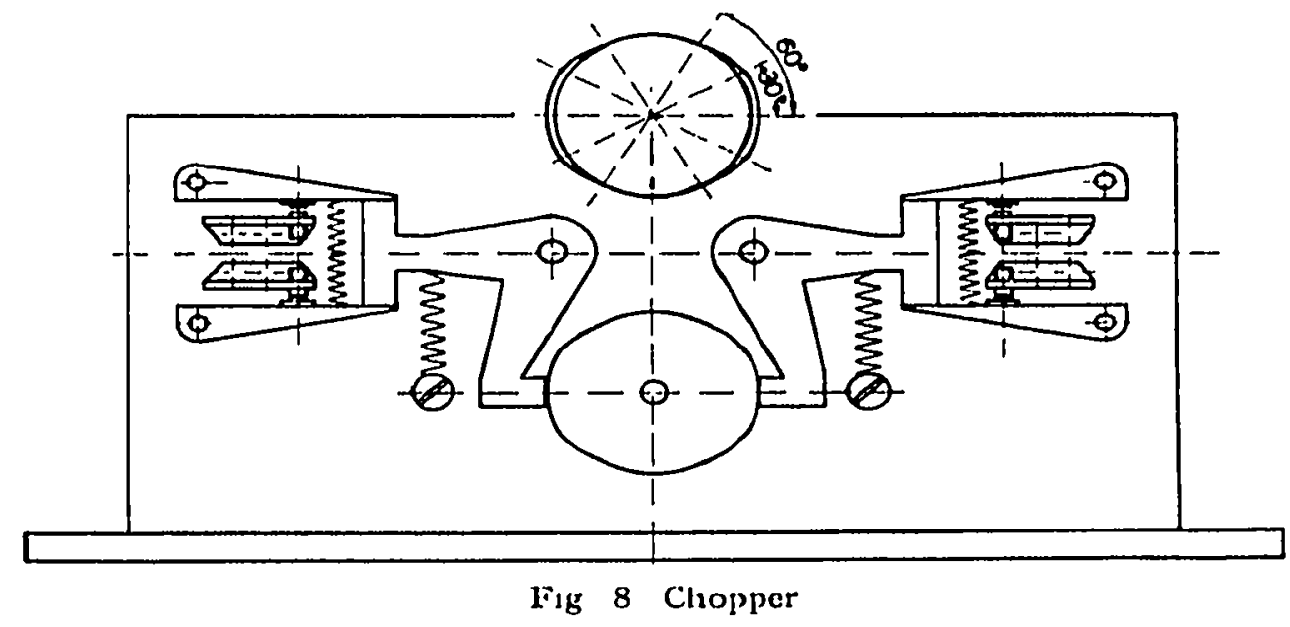

The contacts are lifted by means of rotating discs driven by one and the same synchronous motor. The disc has a special shape (sec insertion in $F_{1 g} 8$ ) in order to obtain a higl speed of opening and closing of the contacts without causing large displacements of the contacts. This way of opening and closing contacts may have advantages over the method used by IIsroN and coworkers; it reduces heat development and possible chattering.

\section{Expcrimental detazls}

The determmation of a heating curve is carried out in the following way The measuring vessel is filled with a weighed amount of substance Usually quantities less than $500 \mathrm{mg}$ are sufficient. The measuring thermometer is inserted into the measuring vessel containing the molten substance

Care is taken that the sensitive part of the thermometer is at equal distance from the bottom and the inner wall of the measuring vessel. The level of the molten substance has to be about $2 \mathrm{~mm}$ above the top of the sensi tive part of the thermometer. Eventually trapped air-bubbles are removed by gentle tapping. Then the substance is allowed to solidify and the measuring vessel with the thermometer is inserted in the block. The block is heated by switching the feeding transformer of the heating current to full.

The Wheatstone bridge contains a switch which connects the output of the bridge either to the input of the amplificr or to a $\mathrm{mV}$-meter. By equilibrating the bridge on the $\mathrm{mV}$-meter the temperature of the measuring vessel may be followed with an accuracy of about $x^{\circ}$. 
W'hen the measuring vessel has attained a desired temperature the heating is switched off and the block is allowed to cquilibrate. The variable resistance of the controlling bridge is set on

$$
R_{4}=R_{1}+R_{c}^{\circ} \alpha\left(T_{2}-T_{1}\right)
$$

where $R_{c}{ }^{\circ}$ is the resistance of the controlling thermometer at zero degrees centigrade and $\left(T_{2}-T_{1}\right)$ is the temperature difference to be maintained between the block and the measuring vessel*.

As a rule $\left(T_{2}-T_{1}\right)$ is about $I .5^{\circ} \mathrm{C}$, causing a rate of heating of about $0.3^{\circ} \mathrm{C}$ per minute.

The variable transformer feeding the heating element is adjusted to such a voltage that it can heat the block at a rate somewhat higher than desired. Provided the voltage is high enough, the setting of the variable transformer is not very critical since the controlling system may reduce the heating current by about $30 \%$ when the temperature of the block is only $0.03^{\circ} \mathrm{high}$.

The amplifier(s) and the recorder are started and the apparatus records the heating curve. The sensitivity of the aparatus may be varied by means of a sivitch changing the back feed of the amplifier.

When the recorder shows full deflection, $R_{3}$ is increased by a distinct amount, and the recording pen returns to near zero deflection

The number of times $R_{3}$ has to be increased during a determination depends on the temperature range to be investigated and the sensitivity sivitched on The sensitivity may be set so that a full scale deflection $(\mathrm{Io} \mathrm{cm}$ ) of the recorder corresponds with 0.12 , $025,0.40$ or $3.5^{\circ} \mathrm{C}$.

Ihe apparatus shows a rapid response. When the voltage of the heating current is suddenly changed by about $25 \%$ the heating current is fully readjusted within 45 seconds. When the resistance $R_{3}$ is changed so that the recording pen travels over the full scale it attains its new final position within $4^{\prime}$ seconds, whereas over $95 \%$ of the scale is travelled by the pen within one second.

The experience gained so far is restricted to temperatures between 20 and $200^{\circ} \mathrm{C}$ In this range the apparatus operates quite satısfactory. Since the block is contained in a Dewar flask and may be casily cooled we see no objections to determinations at temperatures far below zero. (I he measuring vessel shown is only a simple model. It may be easily changed in such a way that contact between the substance and surrounding air (moist) is prevented.) As a matter of fact, the apparatus is intended to be used both at high as well as at low temperatures.

\section{ACKNOWLIDGEMTNTS}

We are much inclebted to Mr IV ScHooN and Mr C LANNiNG, glass-blowerandinstrument-maker at the Analvical Laboratory of the State University. Utrecht, for their skilful ivork in making resistance thermometers. Further thanks are due to Mr $\mathrm{C}$ V VAN DookN, Mr E G BerNS and Mr C C $\checkmark$ D SPOi 2 for their assistance during the development of this apparatus

\section{SUMMARY}

A description is given of an apparatus for the determination of heating curves by means of the "thin film" method The amount of substance used is about $500 \mathrm{mg}$ "The apparatus permits the

* It is assumed that $R_{1}$ and $R_{2}$ are approximately equal to $R_{3}$

References p. r72 
automatic recording of hedting curves with an accuracy of $0.001^{\circ} \mathrm{C}$ within a range of $02^{\circ} \mathrm{C} B y s i m p l y$ resetting a resistance the next following range of $02^{\circ} \mathrm{C}$ may be recorded Larger ranges may be investigated completely automatically, with a temperature sensitivity inversely proportional to the range, however

The dimensions of the calorimetric part of the apparat us are discussed The thermometers used are platinum resistance thermometers having al resistance of about 600 ohms at room temperature I he diameter of the thermometers is about $65 \mathrm{~mm}$ and their length amounts to $25 \mathrm{~mm}$

$\Lambda$ scheme of the amplification system for recording the temperature and controlling the heating current is presented

The apparatus inaly be used from temperatures of from $200^{\circ} \mathrm{C}$ to far below zero

\section{RTISUME}

Un appareil pein la clétermunation des courbes de chaufage par la "methode du film mince" est clecrit Là quantıté de subst.ınce cinployée est de $500 \mathrm{mg}$ L'appareıl permet l'enregistrement automatique des courbes de challfage avec une precision de $0001^{\circ} \mathrm{C}$ dans un intervalle de $02^{\circ} \mathrm{C}$ En fatsant clianger simplement une résistance, on peut conegistrer l'intervalle de $2^{\circ} \mathrm{C}$ ilivant Des intervalles plus grancls peuvent êtrc ctuclies automatiquenent mas, la sensibilité a la ?empérature etant cependant inversement proportionclle, à l'intervalle etudié

Les dimensions de la partie calorimetrięue de l'appareal sont discut Les Les thermométres employes sont dey thermomètres i resistance de platine avec une résistance de 600 ohms a temperature ordin.ure L.e diametre des thermomètres est de $65 \mathrm{~mm}$ environ, leur longucur de $25 \mathrm{~mm}$

Un schéma du systìme amplifıcateur pour l'enregistrement de la temperature ct le réglage du coutint de chauffige est présenté

I.appareil peut être employé à des templratures allant jusqu'à $200^{\circ} \mathrm{C}$ et juscu'a bien en dessous cle séro

\section{ZUSAMMENFASSUNG}

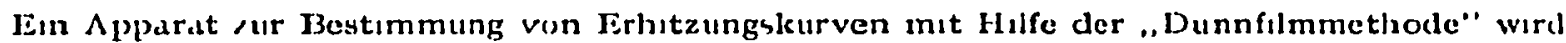
lueschrichen Dic beniutste Substan Aufacichnung von Erhitaungskurven mit einer Genaugkeit von o oo ${ }^{\circ} \mathrm{C}$ in einem $B e r e i c h e$ von o $2^{\circ} \mathrm{C}$ Duch einfaches Verstellen enes Widerstandes kann der nachste Bereich von o $2^{\circ} \mathrm{C}$ registriert weiclen Grosyere 13ereiche konnen vollatomatisch untersucht werclen. wobet aber die Temperaturcmpfindlichkeit ungekehrt propos tional dem Bureiche ist

Die Dimenuionen des kalorinietrischen 1 eiles des Apparates werden erortert Die benutaten Thermometer sind Platinwiderstind-Thermometer init einen Widerstand von ungefahr 600 Ohm bei $Z_{1}$ minertempeiatur Der Durchmesser der Thermometer betragt ungeflir $65 \mathrm{~mm}$, die Lange $25 \mathrm{~mm}$

Eın Schemal cles Verstarleungysystem4 aur lemperaturregistrierung und Regelung cles Heisstromes wircl vorgelegt

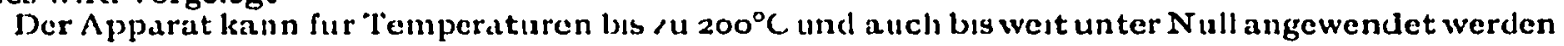

\section{REFERENCES}

- IV M SMI1, Rec trav Ch:1M, 75 (1950) I 309

2 S B. Whomas AND G S l'aklis.J Phys Chem. 35 (r931) 2091

3 W M Smir, Anal Chzirl Ala, I 7 (1957) 23

- M D I.iston, C E Quin, W. E SArgenNr And G G Scotr, Rev Scz Instr, 17 (1946) 194 